\title{
Sustainability in healthcare: efficiency, effectiveness, economics and the environment
}

Welcome to the summer 2018 edition of Future Healthcare Journal. Following the successful focus on end-of-life care in the previous edition, this edition of the journal turns its attention to the issue of sustainability. We have tried to cover many of the domains that are encompassed in this poorly understood and often overlooked area of healthcare, once again presenting a series of focused articles, in conjunction with other papers in this month's Clinical Medicine.

The articles in this edition of $\mathrm{FH}$ J present information on the breadth of issues that healthcare professionals should consider with regards to sustainability, including how we redefine quality in a sustainable healthcare system. This includes how to consider quality improvement, incorporating additional cultural, societal and environmental issues that maximise the likelihood of a sustainable system; ${ }^{1}$ how to account for sustainability issues financially; ${ }^{2}$ and how to assess overall organisational impact. ${ }^{3}$

Sustainability incorporates many core topics integral to $\mathrm{FHJ}$, including quality improvement, process and systems design, and workforce planning issues across an integrated healthcare system. As pointed out by several authors, the size of the NHS workforce and the way we choose to travel to work, deliver our care and procure our material all significantly impact on the environment. In a hard-hitting editorial the mayor of London highlights the political challenges we face in tackling air pollution, both in London and beyond ${ }^{4}$ (a topic of recent policy efforts of the $R\left(P^{5}\right.$ ), and challenges us to consider how we might consider broader environmental issues, for example when we bring people (usually multiple times) back to clinics and for specialist investigations.

While delivering care at home and remotely via telemedicine or telephone clinics is clearly not appropriate for all, the use of innovative, or even simple, digital technology routinely (for example to allow coordination of investigations at a single return visit) may bring broader societal and environmental benefits, that if not embedded may lead to unnecessary risk to all. Of course, the perverse incentives that drive us to maintain these models of care must also be addressed, as eloquently outlined by Rupert Dunbar-Rees. 6
Considering sustainability from a clinical perspective means allocating resources appropriately (both human and material) and considering the health and wellbeing of staff - arguably the single most important entity in the sustainable delivery of healthcare. The first of these issues is highlighted in an article on geriatric surgical liaison teams, which appear to ensure not only that the right individuals are operated on, but that those that are stay in hospital for less time, reducing costs and subsequent post-operative morbidity. ${ }^{7}$

In addition to these important areas, this edition also offers interesting articles addressing patient safety, business case development and non-clinical skills to enable appropriate task prioritisation and resilience. All-in-all this is a fully loaded edition of $\mathrm{FHJ}$ and I hope you enjoy reading it.

\section{References}

1 Mortimer F, Isherwood J, Wilkinson A, Vaux E. Sustainability in quality improvement: redefining value. Future Healthcare J 2018;5:88-93.

2 De Preux L, Rizmie D. Beyond financial efficiency to support environmental sustainability in economic evaluations. Future Healthcare ] 2018;5:103-7.

3 Mortimer F, Isherwood J, Pearce M, Kenward C, Vaux E. Sustainability in quality improvement: measuring impact. Future Healthcare ] 2018:5:94-7.

4 Khan S. The London mayor's views on sustainability. Future Healthcare J 2018;5:84.

5 Royal College of Physicians. Every breath we take: the lifelong impact of air pollution. RCP, 2016. www.rcplondon.ac.uk/projects/outputs/ every-breath-we-take-lifelong-impact-air-pollution [Accessed 8 May 2018].

6 Dunbar-Rees R. Paying for what matters most: the future of outcomes-based payments in healthcare. Future Healthcare ] 2018;5:98-102.

7 Shipway D, Koizia L, Winterkorn $\mathrm{N}$ et al. Embedded geriatric surgical liaison is associated with reduced inpatient length of stay in older patients admitted for gastrointestinal surgery. Future Healthcare ] 2018;5:108-16.

Wing Commander Ed Nicol Editor-in-chief

$\begin{array}{ll}\text { Members of the editorial board } & \\ \text { Wing Commander Edward Nicol } & \text { Dr Mohsin Choudry } \\ \text { Editor-in-chief } & \text { Dr John Dean } \\ \text { Professor Tom Downes } & \text { Professor Paul Jenkins } \\ \text { Deputy editor-in-chief } & \text { Dr Robert Klaber } \\ \text { Editorial board } & \text { Dr David Morgan-Jones } \\ \text { Dr Na'eem Ahmed } & \text { Dr Victoria Simpkin } \\ \text { Debra Armstrong } & \text { Dr Joanna Szram } \\ \end{array}$

Dr Louella Vaughan Ms Sheena Visram Dr Katharine Warburton Dr Stephen Webb Miss Jenny Isherwood
Future Hospital Programme Dr Frank Joseph Dr Mark Temple 